\title{
Membranes for the Sulfur-lodine Integrated Laboratory Scale Demonstration
}

\author{
Frederick F. Stewart
}

August 2007



The INL is a U.S. Department of Energy National Laboratory operated by Battelle Energy Alliance 
INL/EXT-07-13099

\title{
Membranes for the Sulfur-lodine Integrated Laboratory Scale Demonstration
}

\author{
Frederick F. Stewart
}

August 2007

\author{
Idaho National Laboratory \\ Chemical Sciences Department \\ Idaho Falls, Idaho 83415
}

Prepared for the

U.S. Department of Energy

Office of Nuclear Energy

Under DOE Idaho Operations Office

Contract DE-AC07-05ID14517 
INL/EXT-07-13099

This page intentionally left blank. 
INL/EXT-07-13099

\section{ABSTRACT}

INL has developed polymeric membrane-based chemical separations to enable the thermochemical production of hydrogen. Major activities included studies of sulfuric acid concentration membranes, hydriodic acid concentration membranes, $\mathrm{SO}_{2} / \mathrm{O}_{2}$ separation membranes, potential applications of a catalyst reactor system for the decomposition of HI, and evaluation of the chemical separation needs for alternate thermochemical cycles. Membranes for the concentration of sulfuric acid were studied using pervaporation. The goal of this task was to offer the sulfur-iodine (S-I) and the hybrid sulfur (HyS) cycles a method to concentrate the sulfuric acid containing effluent from the decomposer without boiling. In this work, sulfuric acid decomposer effluent needs to be concentrated from $\sim 50 \%$ acid to $80 \%$. This task continued FY 2006 efforts to characterize water selective membranes for use in sulfuric acid concentration. In FY 2007, experiments were conducted to provide specific information, including transmembrane fluxes, separation factors, and membrane durability, necessary for proper decision making on the potential inclusion of this process into the S-I or HyS Integrated Laboratory Scale demonstration. 
INL/EXT-07-13099

This page intentionally left blank. 
INL/EXT-07-13099

\section{CONTENTS}

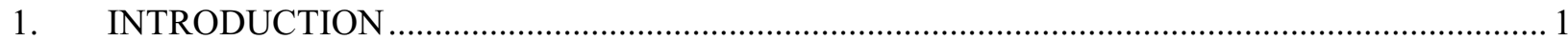

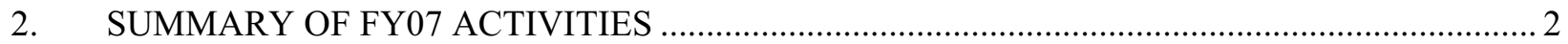

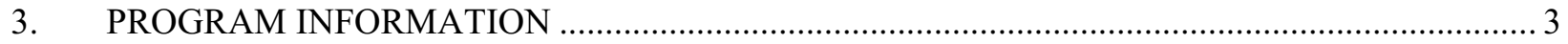



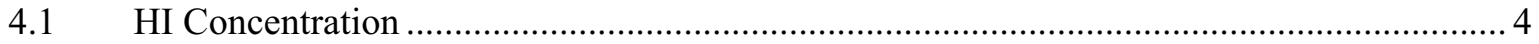

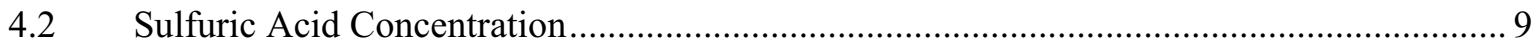

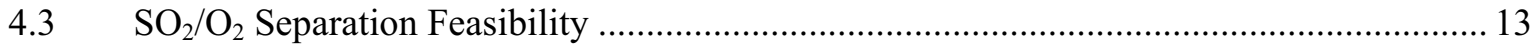

4.4 Catalyst-Membrane Reactor (CMR) Feasibility .......................................................... 16

4.4 Alternate Cycle Membrane Separations Needs and Applications ..................................... 17

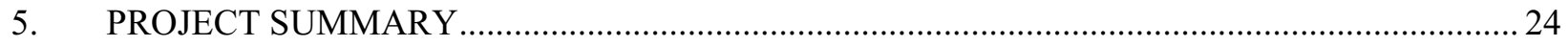

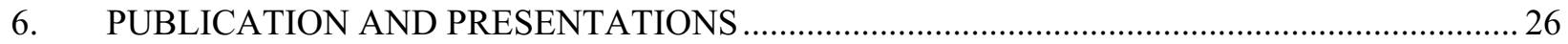

\section{FIGURES}

1 Pervaporation System 4

2 Permeability plot for Nafion-117® (○) and Nafion-112® $(\bullet)$ membranes using an HI 6 feed at $134^{\circ} \mathrm{C}$

3 Membrane performance data for backside pressures of 13 and 39 Torr (1 to r) 6

4 Performance of Nafion-117® membranes at 59, 82, 120, and 163 Torr permeate side 7 pressure

5 Nafion-117® membrane performance at 203 Torr permeate side pressure $\quad 7$

6 Permeability vs. percent HI in feed for variable pressure experiments (left) and vs. $\quad 8$ permeate side pressure (right)

7 Performance of Nafion-112® membranes for the concentration of $\mathrm{H}_{2} \mathrm{SO}_{4}$ at $100{ }^{\circ} \mathrm{C} \quad 10$ (left) and $120^{\circ} \mathrm{C}$ (right)

8 Performance of a Nafion- $117 \AA$ membrane at $120^{\circ} \mathrm{C}$ for the concentration of water 11

9 Permeability of water as a function of the feed sulfuric acid content 12

10 Permeability vs. mole fraction acid in feed 12

11 P- $\alpha$ plot for selected membranes $\quad 15$

12 Schematic diagram of a lab-scale CMR characterization system 16

\section{TABLES}

1 Gas data for selected polymers. 
INL/EXT-07-13099

This page intentionally left blank. 
INL/EXT-07-13099

\section{INTRODUCTION}

INL has developed polymeric membrane-based chemical separations to enable the thermochemical production of hydrogen. Major activities included studies of sulfuric acid concentration membranes, hydriodic acid concentration membranes, $\mathrm{SO}_{2} / \mathrm{O}_{2}$ separation membranes, potential applications of a catalyst reactor system for the decomposition of $\mathrm{HI}$, and evaluation of the chemical separation needs for alternate thermochemical cycles. Membranes for the concentration of sulfuric acid were studied using pervaporation. The goal of this task was to offer the sulfur-iodine (S-I) and the hybrid sulfur (HyS) cycles a method to concentrate the sulfuric acid containing effluent from the decomposer without boiling. In this work, sulfuric acid decomposer effluent needs to be concentrated from $\sim 50 \%$ acid to $80 \%$. This task continued FY 2006 efforts to characterize water selective membranes for use in sulfuric acid concentration. In FY 2007, experiments were conducted to provide specific information, including transmembrane fluxes, separation factors, and membrane durability, necessary for proper decision making on the potential inclusion of this process into the S-I or HyS Integrated Laboratory Scale (ILS) demonstration.

Membranes for the concentration of hydriodic acid also were studied using pervaporation. The focus of the FY 2007 effort was on the operational parameters, rather than materials selection. Most importantly, a series of experiments were conducted by varying the pressure on the backside (permeate) of Nafion-117 ${ }^{\circledR}$ membranes. Trade-offs between increased separation factors and increased process efficiency (at operation closer to atmospheric pressure) provided information needed to make a decision on whether this technology has value to the S-I

process and should be included in the ILS. The data obtained from this work will be evaluated in collaboration with General Atomics (GA).

Tasks also were included for evaluation of the chemical separation needs for alternate thermochemical cycles, for assessment of the feasibility of an $\mathrm{HI}$ catalyst membrane reactor, for collaboration with GA on implementation of membrane processes to the S-I ILS, and for reporting. An additional activity was a study of membranes with the potential to separate $\mathrm{SO}_{2}$ from $\mathrm{O}_{2}$. 


\section{SUMMARY OF FY07 ACTIVITIES}

The following activities were conducted in FY07:

1. The HI pervaporation system was modified for precise control of backside pressure and operated for the HI concentration FY 2007 workscope that began in the latter half of December.

2. Experiments were conducted on the concentration of sulfuric acid (Task 1) at 100 ${ }^{\circ} \mathrm{C}$ and $120^{\circ} \mathrm{C}$ using both Nafion- $117 \circledR$ and Nafion- $112 ®$ membranes. On Task 2 (HI concentration task) experiments were conducted at seven different backside pressures. Conclusions drawn from this work are discussed in this report.

3. During November, the project principal investigator presented a paper at the Fall Annual Meeting of the American Institute of Chemical Engineers (AICHE) detailing the progress to-date on membranes for acid concentration.

4. The progress of the project during FY 2006 was reviewed when the PI attended the annual NHI program review in late October.

5. A manuscript entitled "Pervaporation of Water from Aqueous Hydriodic Acid and Hydriodic Acid/Iodine Mixtures Using Nafion Membranes" was submitted in October 2006 to Journal of Membrane Science and was accepted for publication in July 2007.

6. At the end of January, the project principal investigator submitted a paper entitled "Membrane Separation Processes for the Benefit of the Sulfur-Iodine and Hybrid Sulfur Thermochemical Cycles" to the NTD for inclusion in a special topics issue of International Journal of Hydrogen Energy detailing the progress to-date on membranes for acid concentration for application to the S-I thermochemical cycle. This completed a level 3 milestone.

7. A draft report addressing recommendations of membranes for lower temperature separations was submitted to the NTD on 2/28/2007 (this completed a level 2 milestone due 3/1/2007).

8. The PI attended a meeting at GA in March addressing membrane and catalyst issues with regard to the S-I process and S-I ILS demonstration. From this meeting, action items were assigned to each participant. INL was tasked to provide GA with a membrane module containing a hydrogen separation membrane for testing against gaseous HI. Further, INL was asked to determine the applicability of polymeric membranes for the separation of $\mathrm{SO} 2$ from $\mathrm{O} 2$ at $30^{\circ} \mathrm{C}$. A report was written and submitted to both GA and the NTD in March discussing membranes that have potential for the separation.

9. A submission entitled "Membrane Separations Technology for the Sulfur-Iodine Thermochemical Cycle" was submitted in March for presentation to the Nuclear 
INL/EXT-07-13099

Engineering Division at the Annual AICHE meeting in Salt Lake City, UT scheduled for November 2007. An additional paper discussing acid concentration was submitted to the Separations Division.

10. At the end of May, the project principal investigator submitted a report to the NTD detailing separations needs for the alternate chemical cycles. This completed a level 3 milestone.

11. The PI attended the DOE Hydrogen Program review (Arlington, VA) in May and presented a poster discussing the progress to date of the acid concentration membrane project.

\section{PROGRAM INFORMATION}

The following milestones and deliverables were defined in the FY07 work scope:

1) Complete evaluation of recommended low-temperature polymeric membranes in support of the S-I ILS (due 9/1/2007). Completion of this milestone is represented by this report.

2) Recommend low-temperature membranes for the S-I ILS (due 3/1/2007). Completed $2 / 28 / 2007$.

3) Draft report on recommended membranes for the S-I ILS (due 3/1/2007). Completed $2 / 28 / 2007$.

4) Identify low temperature polymeric membrane research needs for the alternative cycles (6/1/2007). Completed 5/23/2007.

5) Submit journal article on polymer membrane thermochemical cycle applications for NHI joint peer reviewed journal submission (due 1/31/2007). Completed 1/30/2007.

6) Quarterly reporting and draft report on evaluation of membranes for the S-I ILS (due 9/1/2007). Completed on schedule. 
INL/EXT-07-13099

\section{TECHNICAL ACCOMPLISHMENTS}

\subsection{HI Concentration}

Pervaporation data has been generated on the system described here. A diagram of a typical pervaporation apparatus is shown in Fig. 1. The heart of the system is the membrane cell. A $47 \mathrm{~mm}$ stainless steel filtration cell modified for feed side flow was used to secure the membrane with the following alteration. In place of the stainless steel cell half on the wetted upstream (feed) side of the membrane, a replacement was machined from solid Teflon ${ }^{\circledR}$ and fitted with Teflon ${ }^{\circledR}$ bayonet fittings for attachment of tubing. Pumping is provided by a peristaltic pump using $1 / 4$ inch Viton ${ }^{\circledR}$ pumping tubes to connect the cell to the pump and the feed reservoir. Initial experiments using the $\mathrm{HI} /$ water feeds indicated that this apparatus worked well, although the Viton ${ }^{\circledR}$ pumping tube showed limited pumping

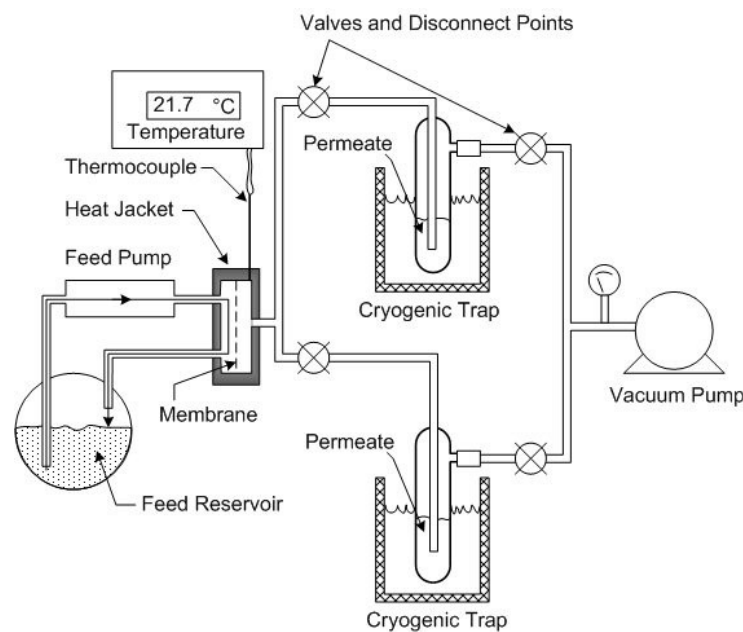

Figure 1. Pervaporation System. life, necessitating periodic replacement. A critical change that was necessary for the sulfuric acid work was a replacement of the Viton ${ }^{\circledR}$ pump tubing with Teflon ${ }^{\circledR}$ lines. Under the conditions of the experiments, sulfuric acid degraded the Viton ${ }^{\circledR}$ tubing within hours.

Maintenance of cell temperatures was accomplished using electrically operated heat tape applied directly to the cell with external shielding of aluminum foil. Additionally, the membrane cell and feed supply reservoir was located in an oven. This "dual zone" heating method was required because cell temperatures in the $120-140{ }^{\circ} \mathrm{C}$ range were difficult to achieve using only the oven because of cell cooling due to feed flow and evaporation of permeate off the backside of the membrane. To achieve the desired cell temperatures, the oven often had to be heated to temperatures as high as $160-170{ }^{\circ} \mathrm{C}$, which adversely affected some of the Teflon ${ }^{\circledR}$ components and also caused spattering of the feed solutions. For experiments at or above $120^{\circ} \mathrm{C}$, the oven was maintained at approximately $90{ }^{\circ} \mathrm{C}$, while the heat tape provided localized heat to the cell itself to boost it to the desired temperature. Temperature was monitored using a properly calibrated thermocouple and pressure was monitored using a Pirani gauge located between the 
INL/EXT-07-13099

vacuum traps and the vacuum pump and was measured using a digital readout. Variable pressure on the membrane backside was achieved by using needle valves, located between the vacuum gauge and the traps, to bleed in air in a controllable fashion.

To characterize any particular membrane's performance, two central factors must be determined. First, is the flux across the membrane, which is the amount of permeate that can be collected off the backside of the membrane per unit membrane area per unit time. Units for flux used in this work were $\mathrm{g} / \mathrm{m} 2 \mathrm{~h}$ (grams of flux per square meter of membrane area per hour). Second, the separation factor must be measured. The separation factor is a relative measure of the membrane's ability to effect the desired separation and is calculated according to equation 1 :

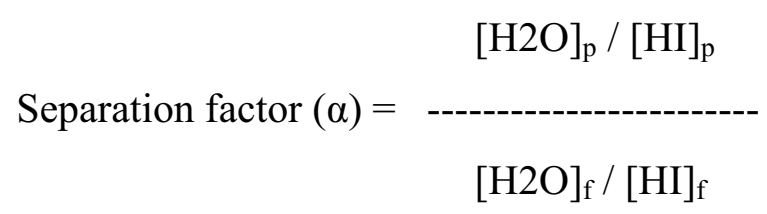

where $[\mathrm{H} 2 \mathrm{O}]_{\mathrm{p}}$ and $[\mathrm{H} 2 \mathrm{O}]_{\mathrm{f}}$ are concentrations of water in the permeate and feed, respectively, as weight percents. Likewise, $[\mathrm{HI}]_{\mathrm{p}}$ and $[\mathrm{HI}]_{\mathrm{f}}$ refer to the $\mathrm{HI}$ concentrations. From the measurements of flux and pressure, it is possible to calculate intrinsic permeabilities. The relationship between flux and permeability can be described according to Eq. 2,

$$
\mathrm{J}_{\mathrm{i}}=\left(\mathrm{P}_{\mathrm{i}} / 1\right)\left(\mathrm{p}_{\mathrm{if}}-\mathrm{p}_{\mathrm{ip}}\right)
$$

where $P_{i}$ is the permeability of component $i, J_{i}$ is the flux of component $i, 1$ is the membrane thickness, and $p_{i f}$ and $p_{i p}$ are the vapor pressures of $i$ in the feed and the permeate, respectively. To simplify the calculation, ideality is assumed on the feed side of the membrane for determination of the vapor pressure of water and Henry's law was applied. On the permeate side, the concentration of HI is sufficiently low that it can be ignored. Permeabilities are reported in units of $\mathrm{g} \mu \mathrm{m} / \mathrm{m}^{2} \mathrm{~h} \mathrm{cmHg}$.

Using the relationship described in Eq. 2, permeabilities were calculated for Nafion-112® and Nafion-117® data sets, Fig. 2. It can be seen that there is a close correspondence between the permeabilities of both polymers. However, this is to be expected since what Eq. 2 does is normalize the data for membrane thickness and pressure differential $(\Delta \mathrm{P})$ across the membrane. 
INL/EXT-07-13099

Most significant to this study is the normalization of the membrane thickness term. In fact, the permeabilities of these two membranes should be similar since they share a similar morphology.

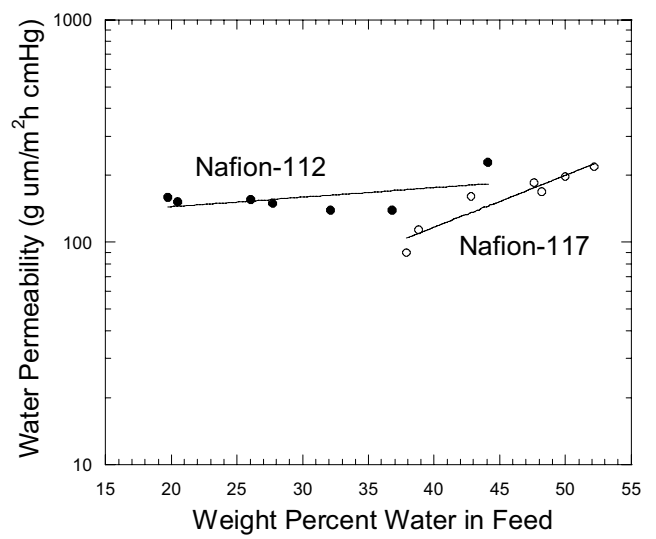

Figure 2. Permeability plot for Nafion-117® (०) and Nafion-112® (•) membranes using an HI feed at $134^{\circ} \mathrm{C}$.

Pervaporation experiments were conducted using HI/water feed and Nafion-117® membranes at differing permeate side pressures. The first two experiments were conducted at average backside pressures of 13 and 39 Torr, which equates into a $\Delta \mathrm{P}$ across the membrane of 634 and 608 Torr, respectively, see Fig 3. In these data, we see membrane performance in terms of both the flux and separation factor. Data collected at these pressures show the same trend of little loss in performance as a function of pressure.


Figure 3. Membrane performance data for backside pressures of 13 and 39 Torr (1 to r).

Further experiments collected at a backside pressures of 59 Torr $(\Delta \mathrm{P}=588$ Torr $), 82$ Torr ( $\Delta \mathrm{P}=565$ Torr $), 120$ Torr $(\Delta \mathrm{P}=527$ Torr $)$, and 163 Torr $(\Delta \mathrm{P}=484$ Torr $)$ are shown in Figure 4. 
INL/EXT-07-13099
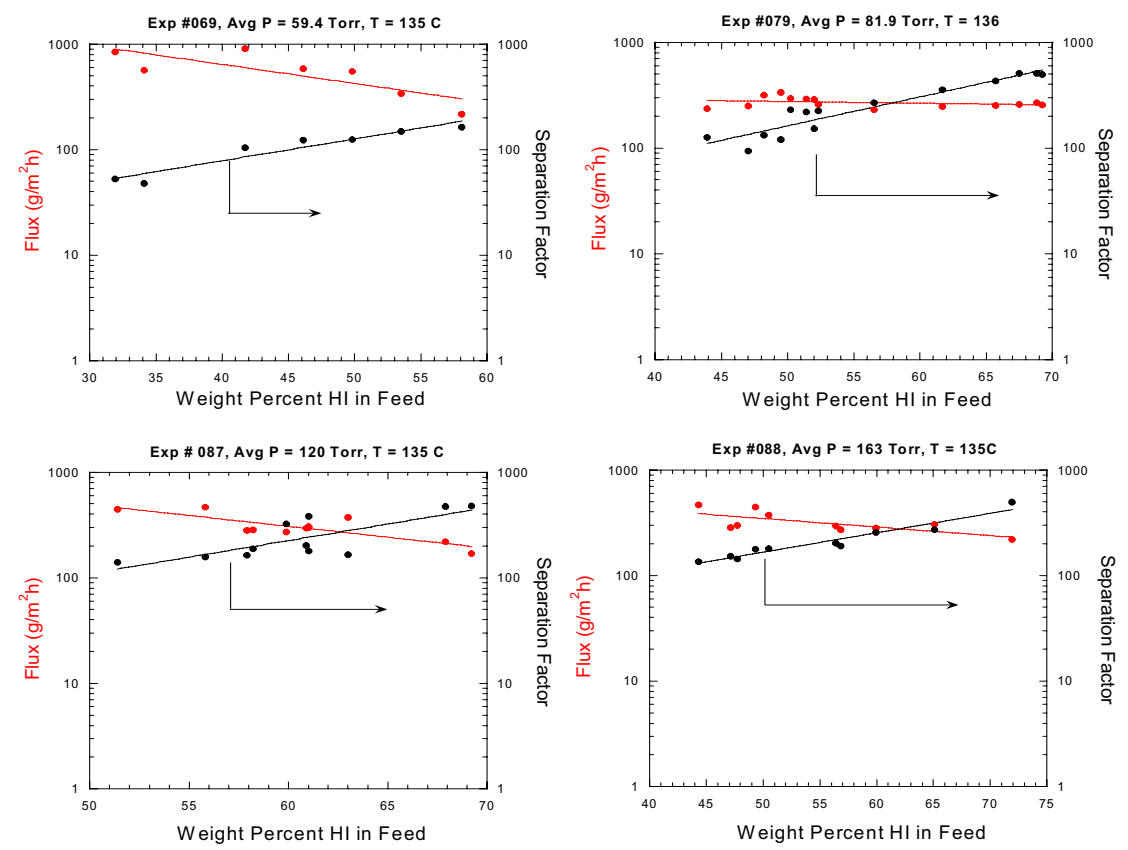

Figure 4. Performance of Nafion- $117 \circledR$ membranes at 59, 82, 120, and 163 Torr permeate side pressure.

An additional data set was collected at 203 Torr $(\Delta \mathrm{P}=444$ Torr $)$. At this pressure, performance is similar to the other experiments, see Fig. 5.



Figure 5. Nafion-117® membrane performance at 203 Torr permeate side pressure.

Variation in the pervaporation data is evident, which could be a simple embodiment of experimental error. More significantly, there does not seem to be a trend of either improving or decreasing performance with respect to backside pressure by a simple analysis of the raw flux/separation factor data. However, general trends can be observed when the data is presented 
in terms of permeability. This is shown in Fig. 6, which shows the calculated permeabilities with respect to feed HI concentration. Using exponential regressions of the data, permeabilities can be calculated in terms of the pressure and feed water content. Some dependence of permeability on pressure can be observed where permeability decreases with increasing permeate side pressure and that this dependence increases with increasing water concentration. This is most pronounced for the $80 \%$ water example, however there is a large amount of scatter in the data. At low water concentrations, there was no observed decrease in performance with decreased driving force suggesting that high vacuum is not necessary for this process to operate. Furthermore, at higher vacuum, small amounts of iodine transport are evident by slightly colored permeate samples. At higher backside pressures ( $>50$ Torr), all permeate samples were colorless.
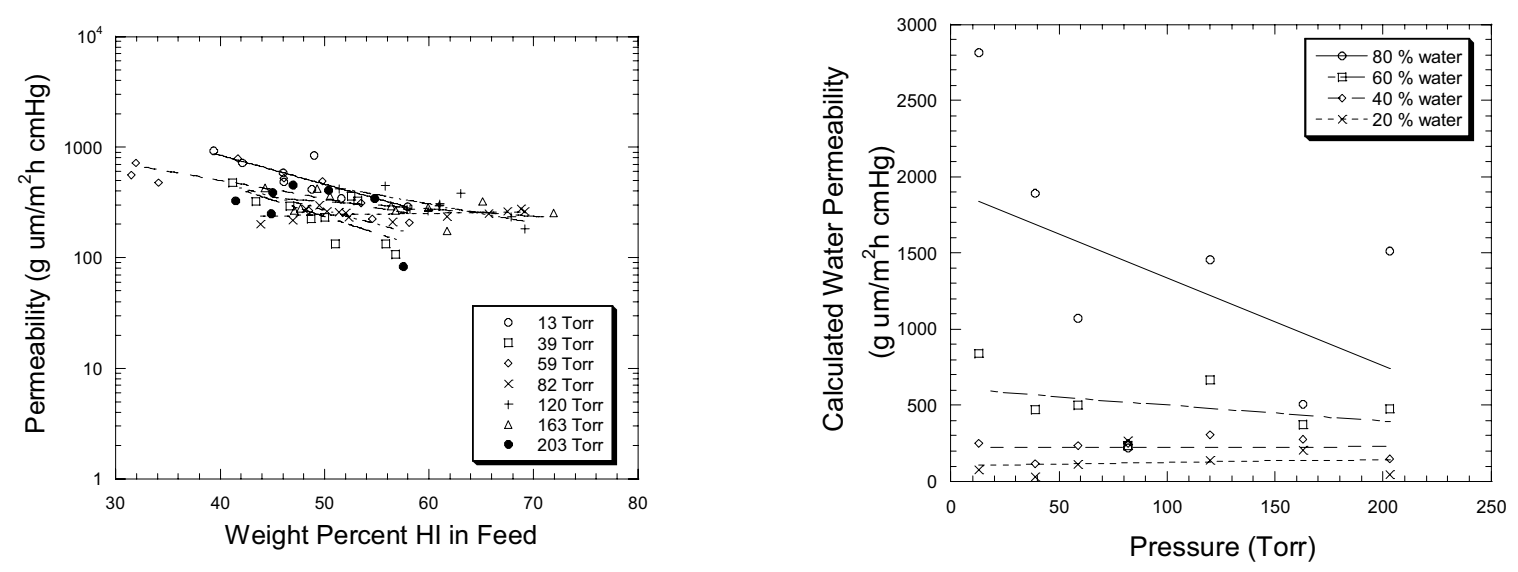

Figure 6. Permeability vs. percent $\mathrm{HI}$ in feed for variable pressure experiments (left) and vs. permeate side pressure (right).

It should be noted that the requirement for vacuum is due to the need to provide a driving force across the membrane and it is the purpose of this task to explore this driving force. Thermodynamically, vaporization of water requires a certain amount of heat per mole to undergo the phase change from liquid to gas. The heat for this can possibly be obtained from the S-I plant and preliminary ASPEN modeling performed at GA has suggested that this necessary heat can indeed be found in the process, thus making pervaporation energy neutral. Alone, this would suggest that the best that can be obtained is "break even"; however this does not consider process improvements and efficiencies that can be obtained by removal of water at strategic positions within the cycle. Further, the removal of water may allow for the lowering of the amount of 
INL/EXT-07-13099

iodine required for the Bunsen product separation, due to the fact that excess iodine precipitates from aqueous $\mathrm{HI}$ as the water is removed. Lowering the iodine may be desirable due to large quantities that are currently required by the full scale $50 \mathrm{MW}$ plant flowsheet.

The permeability of membranes that share a common morphology to any particular permeant should remain roughly constant regardless of thickness. Thus, from permeability measurements, fluxes from membranes of differing thicknesses can be calculated. If the heat can be found to provide for the required water phase change, the issue of efficiency comes down to plant level where we want to have the highest fluxes possible while still maintaining high separation. Higher flux equates to smaller pervaporation plant footprints and lower capital, maintenance, and operating costs. Using the permeability data, performance of thinner membranes can be estimated. For example, using the 163 Torr data set as a guide, performance that ranges from $200-400 \mathrm{~g} / \mathrm{m}^{2} \mathrm{~h}$ for Nafion-117 (180 $\mu \mathrm{m}$ thick) could potentially increase to $4000-8000 \mathrm{~g} / \mathrm{m}^{2} \mathrm{~h}$ using a membrane that was $10 \mu \mathrm{m}$ thick. Increasing performance by a factor of 20 could potentially reduce the needed membrane area by that amount. However, at higher fluxes, concentration polarization (CP) becomes and issue. $\mathrm{CP}$ is a boundary layer issue at the membrane surface. With the transport of a highly permeable species, a boundary layer at the membrane surface can form that is depleted of permeant resulting in a zone highly concentrated with rejectate in direct contact with membrane. Without adequate mixing, transport of rejectate increases due to its higher concentration at the feed/membrane interface. Higher transport of rejectate equates to lower separation factors and less membrane system efficiency. Thus, it is recommended that thinner membranes be characterized for performance and boundary layer issues to provide the most effect separation system possible for inclusion in the S-I ILS.

\subsection{Sulfuric Acid Concentration}

The purpose of this task is to develop a capability to concentrate sulfuric acid at subboiling temperatures. Boiling sulfuric acid, as occurs in distillation, creates significant materials issues due to the corrosiveness of the acid at the vapor-liquid interface. In fact, dilute sulfuric acid is more corrosive than concentrated acid. The decomposition of sulfuric acid is equilibrium limited, which means that the reaction does not go to completion. With the decomposition of a mole of sulfuric acid, a mole of water is liberated. Thus, the effluent of the decomposition 
reactor, other than $\mathrm{SO}_{2}$ and $\mathrm{O}_{2}$, is diluted sulfuric acid. Recycle of this stream requires concentration prior to re-entry into the reactor.

To develop this capability, data derived from the HI concentration effort using pervaporation was used as a guide. A significant issue for this application is membrane durability due to the corrosiveness of the acid. An additional complication is that sulfuric acid is also a strong oxidizer, which HI is not. Thus, the potential for membrane degradation could have been greater from sulfuric acid, as opposed to the HI feed.

Using Nafion-112® membranes, we have demonstrated high levels of pervaporation performance at both $100{ }^{\circ} \mathrm{C}$ and $120^{\circ} \mathrm{C}$, see Figure 7. These data are presented similarly to the HI work, in terms of weight percent acid in the feed. Also observed is the now common relationship between acid concentration and flux with higher fluxes at lower acid concentrations. Magnitudes of these fluxes tend to be large, ranging from 100 to $1000 \mathrm{~g} / \mathrm{m}^{2} \mathrm{~h}$ depending on concentration. Likewise, increasing separation factors with increasing acid concentration also have been observed. This is due to the fairly steady permeate acid concentration with respect to feed acid content. The most startling observation is the size of the separation factors, which tend to be one to two orders of magnitude higher than the corresponding HI experiments. This may be due to the lower volatility of sulfuric acid as compared to HI.
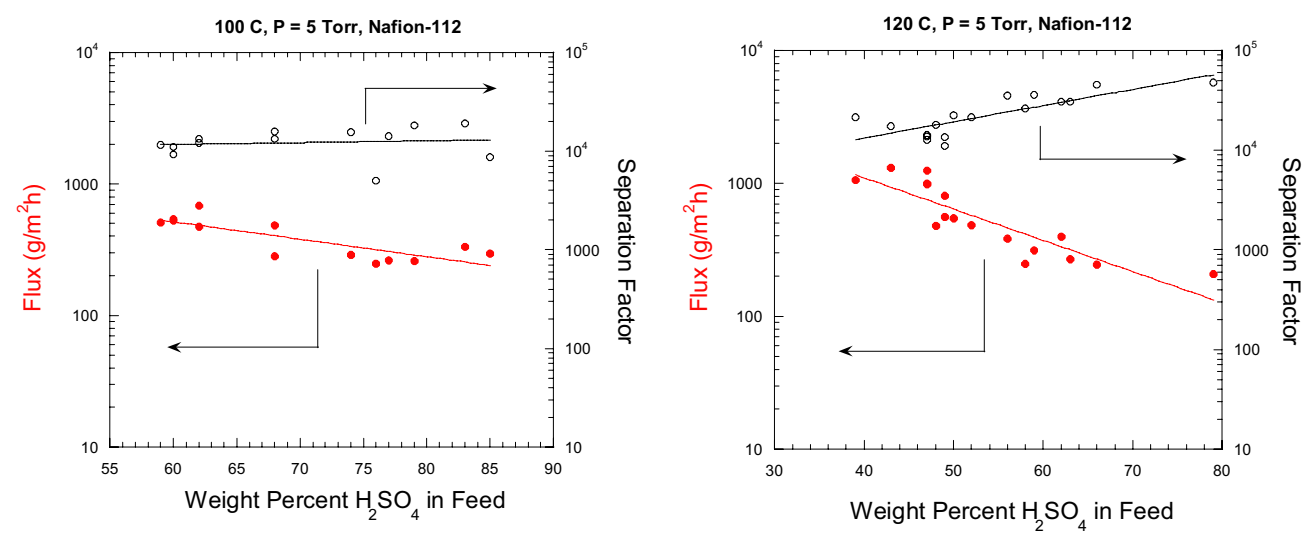

Figure 7. Performance of Nafion- $112 \AA$ membranes for the concentration of $\mathrm{H}_{2} \mathrm{SO}_{4}$ at $100{ }^{\circ} \mathrm{C}$ (left) and $120{ }^{\circ} \mathrm{C}$ (right).

A Nafion-117® membrane was studied at $120^{\circ} \mathrm{C}$, as shown in Figure 8. In this experiment, the most notable feature was the slope of the separation factor regression in which the separation factors decreased with increasing acid concentration, contrary to the other 
experiments. It is not clear at this time why this behavior was observed; this is the subject of further study. In terms of membrane flux, this data does provide a direct comparison to the Nafion- $112 \AA$ experiment at the same temperature to assess the significance of membrane thickness. Fluxes of water were generally greater for the thinner Nafion- $112 \AA$ membrane at similar concentrations, although the effect became less pronounced as the acid concentration increased. Increased transmembrane flux equates into a smaller membrane area required to handle the desired amount of permeate, which then can result in lower membrane module capital and operating costs.

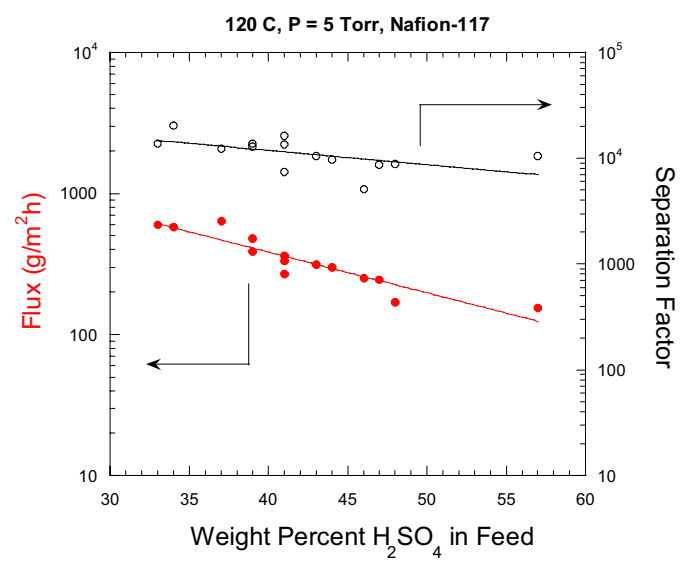

Figure 8. Performance of a Nafion- $117{ }^{\circledR}$ membrane at $120^{\circ} \mathrm{C}$ for the concentration of water.

A calculation of permeability, similar to that performed using the HI concentration data, determined that the mechanism of water transport in aqueous sulfuric acid is the same regardless of membrane thickness, as shown in Figure 9. In this plot, permeabilities are compared for experiments conducted at $120^{\circ} \mathrm{C}$ using both Nafion- $112 \AA$ and Nafion- $117 ®$ membranes at 5 Torr and 25 Torr permeate side pressures. The close correspondence of the data suggests that water interacts with and transports through both membranes with a similar mechanism and that the membrane morphologies are also similar. 
INL/EXT-07-13099

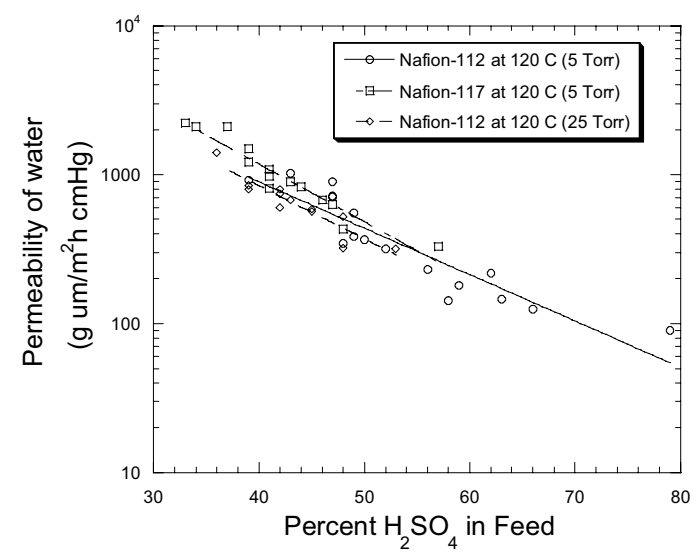

Figure 9. Permeability of water as a function of the feed sulfuric acid content.

A direct comparison of water permeability in $\mathrm{HI}$ and $\mathrm{H}_{2} \mathrm{SO}_{4}$ containing feeds was performed. The water content, expressed in terms of mole fraction, is presented with respect to the water permeability, see Figure 10. Shown in the figure is a comparison between all of the $\mathrm{H}_{2} \mathrm{SO}_{4}$ data and the $\mathrm{HI}$ data set taken at 13 Torr backside pressure. A lower permeability at similar concentrations is noted for the HI containing feed. However, the difference is minimal and points to a similar interaction between the acids and the membrane substrates and that the greater oxidation potential of $\mathrm{H}_{2} \mathrm{SO}_{4}$ does not effect transport.



Figure 10. Permeability vs. mole fraction acid in feed. 
INL/EXT-07-13099

\section{3 $\mathrm{SO}_{2} / \mathrm{O}_{2}$ Separation Feasibility}

A determination of candidate membranes for $\mathrm{SO}_{2} / \mathrm{O}_{2}$ separations was prepared during $\mathrm{FY}$ 2007 in response to an action item from the GA visit in March. INL does not have a library of $\mathrm{SO}_{2}$ permeability data through polymer membranes upon which to propose likely materials. However, there is a wealth of data on a variety of polymer materials for transport of permanent gases such as $\mathrm{Ar}, \mathrm{H}_{2}, \mathrm{O}_{2}, \mathrm{~N}_{2}, \mathrm{CH}_{4}$ and $\mathrm{CO}_{2}$. And for a certain class of polymers, polyphosphazenes, there is $\mathrm{H}_{2} \mathrm{~S}$ data. Using this data, we estimated the $\mathrm{SO}_{2}$ permeability. Using critical gas parameters, such as the critical temperature $\left(T_{c}\right)$, we can estimate performance of a gas given that it has a known $\mathrm{T}_{\mathrm{c}}$ value. Plots of gas permeability versus gas $\mathrm{T}_{\mathrm{c}}$ can yield exponential relationships as demonstrated by INL for polyphosphazenes, and by the Freeman group (UT-Austin) for polydimethylsiloxane (PDMS) and poly(trimethylsilylpropyne) (PTMSP). Application of this relationship did yield exponential line fits that were used to predict $\mathrm{SO}_{2}$ permeabilities for a variety of polymers. Determination of the separation potential was accomplished by use of the ideal separation factor $(\alpha)$, which is a simple ratio of the gas permeabilities. For this work, $\alpha\left(\mathrm{SO}_{2} / \mathrm{O}_{2}\right)$ values were calculated from the predicted $\mathrm{SO}_{2}$ values and the actual $\mathrm{O}_{2}$ permeabilities.

Table 1 shows the gas permeability data for selected polymers. Gases include $\mathrm{O}_{2}$ and the predicted values for $\mathrm{SO}_{2}$. From these, the ideal separation factors were calculated. A variety of performances are noted. In general, the more rubbery materials offered the best permeabilities and separation factors. Of the commercially available organic polymers, the copolymer of polystyrene and polybutadiene had perhaps the best overall compromise between the two parameters. The permeability for $\mathrm{SO}_{2}$ was predicted to be 93 Barrers with a separation factor of 155 favoring $\mathrm{SO}_{2}$. However the best performing polymers were from a class of materials called polyphosphazenes. Polyphosphazenes have a backbone of phosphorus and nitrogen with two pendant groups attached to phosphorus providing utility. For example, M2D and M2E are polyphosphazenes having pendant groups that depress the glass transition temperature $\left(\mathrm{T}_{\mathrm{g}}\right)$, forming rubbery membranes. These offered the best performance with predicted $\mathrm{SO}_{2}$ permeabilities from 2000-3000 Barrers, while also having separation factors of $\sim 150$. The polymer with the highest permeability is PTMSP, which has been reported by the Freeman group of having one of the largest fractional free volumes (FFV) of any polymer. Large FFV results in 
INL/EXT-07-13099

very permeable materials. For instance, we have predicted a permeability of over 100,000; however this comes at the expense of separation factor, which was calculated at only 16.5 .

Table 1. Gas data for selected polymers.

\begin{tabular}{|c|c|c|c|}
\hline Polymer & $\begin{array}{l}\mathrm{O}_{2} \text { Permeability } \\
\text { (Barrers) }\end{array}$ & $\begin{array}{c}\mathrm{SO}_{2} \text { Permeability } \\
\text { (predicted in Barrers) }\end{array}$ & $\alpha\left(\mathrm{SO}_{2} / \mathrm{O}_{2}\right)$ \\
\hline M2E & 17.3 & 3050 & 176.3 \\
\hline M2D & 18.1 & 2852 & 157.6 \\
\hline 3-phenyl propoxy & 15 & 1115 & 74.3 \\
\hline Trifluoroethoxy & 81.3 & 855 & 10.5 \\
\hline Eypel-F & 65.1 & 862 & 13.2 \\
\hline M010 & 12.3 & 306 & 24.9 \\
\hline Triton-3 & 10.1 & 220 & 21.8 \\
\hline T014 & 18.9 & 219 & 11.6 \\
\hline Para-fluorophenoxy & 0.4 & 62.5 & 156.3 \\
\hline Triton-2 & 4.9 & 34.7 & 7.1 \\
\hline T018 & 11.01 & 35.7 & 3.2 \\
\hline 33101(рpop) & 6 & 20.3 & 3.4 \\
\hline JP200(ррор) & 1.6 & 16 & 10.0 \\
\hline VTEC $80-051$ & 17.3 & 3050 & 176.3 \\
\hline $\begin{array}{l}\text { Poly(styrene-co- } \\
\text { butadiene) }\end{array}$ & 0.6 & 93 & 155.0 \\
\hline PDMS & 497 & 10932 & 22.0 \\
\hline Poly(styrene) & 2.4 & 53.4 & 22.3 \\
\hline PVC/Plasticized/ & 2.5 & 32 & 12.8 \\
\hline PTMSP & 6131 & 101309 & 16.5 \\
\hline Polysulfone $26 \mathrm{~K}$ & 1.7 & 16.8 & 9.9 \\
\hline Poly(ethylene) & 6.3 & 48.9 & 7.8 \\
\hline CMS- 3 cast & 403 & 2392 & 5.9 \\
\hline PDMS (for reference) & 540 & 3492 & 6.5 \\
\hline CMS-3 purchased & 145 & 822.0 & 5.7 \\
\hline Polystyrene & 2.3 & 8.14 & 3.5 \\
\hline Polysulfone $35 \mathrm{~K}$ & 2.6 & 2.61 & 1.0 \\
\hline PET & 5 & 7.33 & 1.5 \\
\hline PVC/Unplasticized & 1.1 & 1.51 & 1.4 \\
\hline Eval Film & 0.2 & 0.16 & 0.8 \\
\hline Kynar & 1.4 & 1.64 & 1.2 \\
\hline Polysulfone 16K & 9.7 & 3.83 & 0.4 \\
\hline $\begin{array}{l}\text { Poly(methyl } \\
\text { methacrylate) }\end{array}$ & 3.3 & 0.25 & 0.1 \\
\hline
\end{tabular}

A common method of displaying large amounts of gas transport data is the P- $\alpha$ plot, which plots both the permeability and the separation factor on one graph. For this work, $\mathrm{SO}_{2}$ permeability and $\mathrm{SO}_{2} / \mathrm{O}_{2}$ data have been plotted as shown in Figure 11. In this plot, a variety of performances are noted. In general, the glassier polymers tend to be poorer performers. For example, poly(methylmethacrylate) (PMMA), poly(sulfone), and poly(ethylene terephthalate) 
are poor performers both in terms of the permeability and the separation factor. The polyphosphazenes, on the other hand, appear to be well suited to this separation. PTMSP is shown at the far right with the highest permeability; however with a low separation factor. More permeable polymers such as CMS-3 and PDMS also echo this trend. All permeability data used in this study $\left(\mathrm{O}_{2}\right.$ and the other permanent gases $)$ were collected at $30{ }^{\circ} \mathrm{C}$ and a feed side pressure of 2

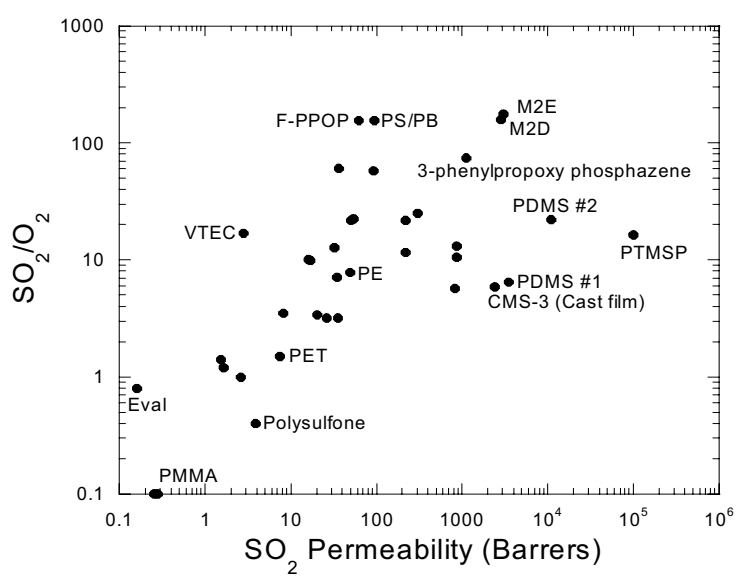

Figure 11. P- $\alpha$ plot for selected membranes. Bar.

The polyphosphazenes screened for this application appear to offer the best performance. Of course, a study to experimentally determine the actual permeabilities and separation factors should be performed to validate these predictions. The value of these predictions lies in the fact that this information can be used to guide decision making concerning which polymers should be initially screened. Furthermore, this information supports the determination that there are membrane materials that can be used for this separation.

Polyphosphazenes are interesting materials in that they can be tailored to specific separation needs. Furthermore, they are generally non-toxic and non-flammable. All formulations have good thermal stability up to a maximum of $\sim 350^{\circ} \mathrm{C}$, depending on the choice of pendant group. Low $\mathrm{T}_{\mathrm{g}}$ materials such as M2D and M2E decompose $\sim 250{ }^{\circ} \mathrm{C}$. Polyphosphazenes also enjoy a high level of chemical stability and are stable in the presence of acid; however they can degrade somewhat in base.

If it were desired to develop this capability for removal of $\mathrm{SO}_{2}$ from the $\mathrm{SO}_{2} / \mathrm{O}_{2}$ mixture to facilitate $\mathrm{SO}_{2}$ cleanup for the Bunsen reaction, two tasks must be addressed:

1) Pure gas permeability of $\mathrm{SO}_{2}$. This can be done easily and the INL currently is equipped to do this characterization.

2) Mixed gas study of the $\mathrm{SO}_{2} / \mathrm{O}_{2}$ mixture. This can be done at INL using a mixed gas system. In these experiments, these gases will be separated, permeabilities measured, and separation factors calculated. This work is especially significant because 
interactions that the gases have not only with the membrane, but with each other, can be assessed.

\subsection{Catalyst-Membrane Reactor (CMR) Feasibility}

In collaboration with Dan Ginosar's team, we have developed a CMR concept for development in FY 2008. This concept employs membrane materials that were identified during FY 2006 work and catalyst materials, which are currently under study by the Ginosar group. Membranes consist of polyimides that are permeable to hydrogen, exhibit much lower HI and I2 permeability, and are stable at temperatures as high as $300^{\circ} \mathrm{C}$. The geometry that would be the most advantageous would be the tube and shell design. In this geometry, a porous tube support is coated on the exterior with a polymer that is selective for hydrogen. The inner space of the tube is then packed with the catalytic material. The tube is then mounted into a shell housing.

Operation of the CMR would have feed entering into the inner catalyst-filled space, dissociation of the HI would yield $\mathrm{I}_{2}$ and $\mathrm{H}_{2}$, and then the $\mathrm{H}_{2}$ exits the reactor through the porous tube and selective polymer to be collected inside the shell. A diagram of the system is shown in Fig. 12. Development of this technology has been proposed as a part of the FY2008 work scope.

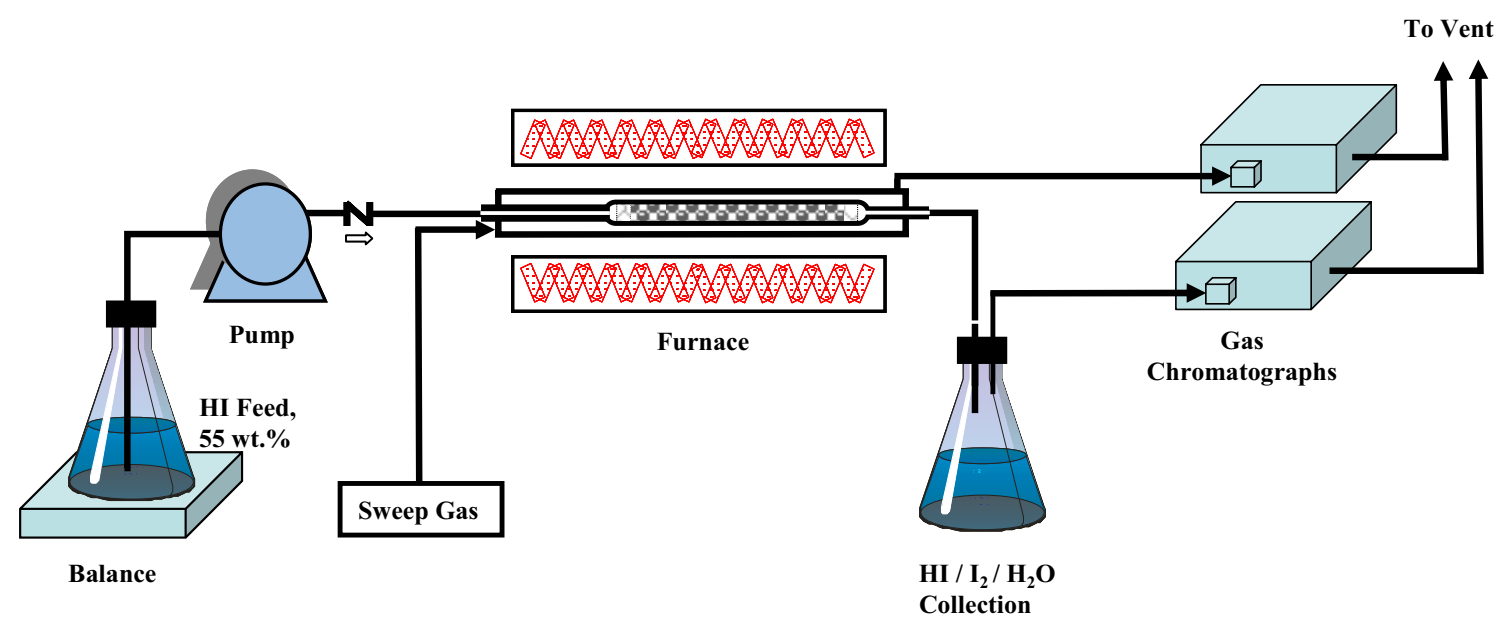

Figure 12. Schematic diagram of a lab-scale CMR characterization system 
INL/EXT-07-13099

\subsection{Alternate Cycle Membrane Separations Needs and Applications}

The bulk of the efforts for the development of a hydrogen production plant supported by NHI have been directed towards the sulfur-iodine (S-I) thermochemical cycle. However, it was judged prudent to re-investigate the more promising alternate chemical cycles in light of new developments and technical accomplishments derived from the current S-I work. In this work, we have sought to analyze the available data for the promising alternate chemical cycles to provide an understanding of their inherent chemical separations needs. However, it should be noted that this report is not intended to be all inclusive due to the fact that physical conditions of each of the processes may be varied as the cycles are developed. Large modifications can create separations issues that are not anticipated in this report.

\subsubsection{Hybrid Chlorine Cycle}

The hybrid chlorine cycle employs two main reactions. The first, the reverse Deacon reaction (eq 3), converts elemental chlorine and water into $\mathrm{HCl}$ and oxygen. Oxygen is removed from the process and the $\mathrm{HCl}$ is decomposed through electrolysis yielding $\mathrm{H}_{2}$ as the desired product and $\mathrm{Cl}_{2}$ gas, which is recycled to the reverse Deacon reaction.
$\mathrm{Cl}_{2}(\mathrm{~g})+\mathrm{H}_{2} \mathrm{O}(\mathrm{g}) \leftrightarrow 2 \mathrm{HCl}(\mathrm{g})+1 / 2 \mathrm{O}_{2}(\mathrm{~g})$
$850^{\circ} \mathrm{C}$
eq 3
$2 \mathrm{HCl}(\mathrm{g}) \leftrightarrow \mathrm{H}_{2}(\mathrm{~g})+\mathrm{Cl}_{2}(\mathrm{~g})$ electrolytic
$75^{\circ} \mathrm{C}$
eq 4

The Gooding group at Clemson University has recognized that the separation of $\mathrm{O}_{2}$ from $\mathrm{HCl}$ (and remaining $\mathrm{Cl}_{2}$ and water) is perhaps the most significant issue and they propose that this can be accomplished using dense ceramic membrane for the removal of $\mathrm{O}_{2}$, or by using an acidic absorber to remove $\mathrm{HCl}$. For their experimental studies of this cycle, they have concentrated on the $\mathrm{HCl}$ absorber technology. However, this approach requires a desorption step to affect recycle of the acid to the reverse Deacon reactor.

Selective oxygen membrane technology has been demonstrated using mixed metal oxide substrates. Mixed metal membranes are of interest for this project due to the expected resistance they should have to both high temperatures and oxidative chemical environments. The first report of a mixed metal oxide membrane exhibiting high oxygen permeability was published in 
INL/EXT-07-13099

1985. ${ }^{\mathrm{a}}$ A more recent paper discussed in detail a method for forming mixed Sr, Co, Fe (SCFO) and $\mathrm{Ba}, \mathrm{Sr}, \mathrm{Co}, \mathrm{Fe}$ (BSCFO) oxide membranes. ${ }^{\mathrm{b}}$ The metals were mixed together in aqueous solution as nitrate salts in EDTA and citric acid. Ammonia was added to adjust the $\mathrm{pH}$ and the solvent was evaporated to yield a purple gel. The gel was then heated to $150{ }^{\circ} \mathrm{C}$ to make a powder that was calcined at $950{ }^{\circ} \mathrm{C}$. Membranes were formed from the powders using a hydraulic press. The membrane disks were then sintered at $1150{ }^{\circ} \mathrm{C}$ for $2-5$ hours yielding a membrane suitable for gas permeance study.

Membranes that were $1.5 \mathrm{~mm}$ thick were examined for $\mathrm{O}_{2}$ permeability. The authors noted that brittleness was a factor in experiments where the temperature was increased to $600{ }^{\circ} \mathrm{C}$ followed by controlled cooling at $1{ }^{\circ} \mathrm{C} / \mathrm{min}$. The BSCFO membrane showed less cracking than the SCFO membrane, suggesting that the BSCFO material has a lower expansion coefficient and better dimensional stability. Both formulations showed direct proportionality between the operating temperature and the $\mathrm{O}_{2}$ flux. At $600{ }^{\circ} \mathrm{C}$, both materials had measured $\mathrm{O}_{2}$ fluxes of 0.1 $\mathrm{mL} / \mathrm{cm}^{2} \mathrm{~min}$. As the temperature was increased to $800{ }^{\circ} \mathrm{C}$, permeability of $\mathrm{O}_{2}$ increased to approximately $1.3 \mathrm{~mL} / \mathrm{cm}^{2} \mathrm{~min}$ for the SCFO membrane and $1.5 \mathrm{~mL} / \mathrm{cm}^{2} \mathrm{~min}$ for the BSCFO membrane.

$\mathrm{O}_{2}$ permeation also showed a positive correlation to the feed-side pressure using a 1.8 $\mathrm{mm}$ thick membrane. At $950^{\circ} \mathrm{C}$, a feed pressure of 0.01 atm $(0.15 \mathrm{psi})$ yielded a permeability of $0.13 \mathrm{~mL} / \mathrm{cm}^{2} \mathrm{~min}$. As the pressure was raised to $1 \mathrm{~atm}(14.9 \mathrm{psi})$, the permeability was measured at $2.1 \mathrm{~mL} / \mathrm{cm}^{2} \mathrm{~min}$. BFSCO membrane durability tests showed good high temperature performance and little loss of transmembrane flux at $850^{\circ} \mathrm{C}$, suggesting that this particular formulation was quite stable.

\subsubsection{Vanadium-Chlorine Cycle}

This cycle is considered in this analysis because of its dependence on the reverse Deacon reaction. The Vanadium-chlorine cycle is a purely thermochemical cycle based upon the reverse Deacon reaction and the oxidation-reduction chemistry of vanadium. One variant of the cycle

\footnotetext{
a Y. Teraoka, H.M. Zhang, S. Furukawa, and N. Yamazoe, “Oxygen Permeation Through Perovskite-Type Oxides", Chem. Lett. $1985,1743$.

${ }^{\mathrm{b}}$ Z. Shao, W. Yang, Y. Cong, H. Dong, J. Tong, and G. Xiong, "Investigation of the Permeation Behavior and Stability $\mathrm{Ba}_{0.8} \mathrm{Sr}_{0.5} \mathrm{Co}_{0.8} \mathrm{Fe}_{0.2} \mathrm{O}_{3-\delta}$ Oxygen Membrane”, J. Membr. Sci. 2000, 172, 177.
} 
INL/EXT-07-13099

consists of one low temperature reaction, one moderate temperature, and two high temperature steps. ${ }^{\mathrm{c}}$

$\begin{array}{ll}2 \mathrm{VCl}_{2}+2 \mathrm{HCl}(\mathrm{g}) \leftrightarrow 2 \mathrm{VCl}_{3}+\mathrm{H}_{2}(\mathrm{~g}) & 25^{\circ} \mathrm{C} \\ 4 \mathrm{VCl}_{3}(\mathrm{~s}) \leftrightarrow 2 \mathrm{VCl}_{4}(\mathrm{~g})+2 \mathrm{VCl}_{2}(\mathrm{~s}) & 750^{\circ} \mathrm{C} \\ 2 \mathrm{VCl}_{4}(\mathrm{l}) \leftrightarrow 2 \mathrm{VCl}_{3}+\mathrm{Cl}_{2}(\mathrm{~g}) & 200^{\circ} \mathrm{C} \\ \mathrm{Cl}(\mathrm{g})+\mathrm{H}_{2} \mathrm{O}(\mathrm{g}) \leftrightarrow 2 \mathrm{HCl}(\mathrm{g})+1 / 2 \mathrm{O}_{2} & 850{ }^{\circ} \mathrm{C}\end{array}$

This cycle has several chemical separations that need to be performed to make the cycle a success. The separations issues discussed with respect to the hybrid chlorine cycle and the reverse Deacon reaction apply here. In a patent application discussing the $\mathrm{V}-\mathrm{Cl}$ cycle by Amendola, a sorbent is used to selective remove the $\mathrm{HCl}$ from $\mathrm{O}_{2}{ }^{\mathrm{d}}$. Liquid amine containing organic sorbents such as monoethanolamine reversibly form complexes with $\mathrm{HCl}$. $\mathrm{HCl}$ can be recovered by heating. An advantage of $\mathrm{HCl}$ removal is that it shifts the equilibrium of the reverse Deacon reaction, thus encouraging increased conversion.

Although not explicitly shown in equations 5-8, water management is an issue that must be addressed. ${ }^{\text {e }}$ In eq. 5, the $\mathrm{HCl}$ is aqueous and hydrates the vanadium(III) chloride product. Thus, water must be driven from the $\mathrm{VCl}_{3}$ prior to any further processing. $\mathrm{VCl}_{3}$ is known to readily dehydrate at $160^{\circ} \mathrm{C}$; however hydrolysis forming vanadium oxide $\left(\mathrm{V}_{2} \mathrm{O}_{3}\right)$ can occur above $130{ }^{\circ} \mathrm{C}$. To address this issue, Knoche has successfully performed the dehydration at lower temperatures using a stripping gas stream of $\mathrm{N}_{2}$, mix of $\mathrm{N}_{2}$ and $\mathrm{HCl}$, and pure $\mathrm{HCl}$ gas. ${ }^{\mathrm{g}}$

In his patent application, Amendola reports two variants of the cycle. In the "dry" version, separations are needed including the removal of $\mathrm{O}_{2}$ from $\mathrm{HCl}$, and dehydration of the $\mathrm{VCl}_{3}$. The dry version consists of three reaction steps:

\footnotetext{
${ }^{\mathrm{c}}$ M. Lewis, "Down Selection of the Four Most Promising Alternative Thermochemical Cycles", Milestone report, Nuclear Hydrogen Initiative, March 31, 2007.

d S. Amendola, "Thermochemical Hydrogen Produced from a Vanadium Decomposition Cycle”, U.S. Patent Application 2005/0013771 A1, January 20, 2005.

${ }^{\mathrm{e}}$ K.F. Knoche, P.Shuster, "Thermochemical Production of Hydrogen by a Vanadium/Chlorine Cycle. Part 1: An Energy and Exergy Analysis of the Process", Int. J. Hydrogen Energy, 1984, 9(6), 457.

${ }^{\mathrm{f}}$ V.V. Pechovskii, N.L. Vorob'ev, “The Reaactions of Vanadium Chlorides with Hydrogen, Oxygen, and Water”, Russ.J. Inorg. Chem. 1984, 10, 778 .

${ }^{\mathrm{g}}$ K.F. Knoche, P. Shuster, T. Ritterbex, "Thermochemical Production of Hydrogen by a Vanadium/Chlorine Cycle. Part 2: Experimental Investigation of the Individual Reaction”, Int. J. Hydrogen Energy, 1984, 9(6), 473.
} 
$\begin{array}{ll}2 \mathrm{VCl}_{3} \leftrightarrow 2 \mathrm{VCl}_{2}+\mathrm{Cl}_{2} & 525^{\circ} \mathrm{C} \\ \mathrm{Cl}(\mathrm{g})+\mathrm{H}_{2} \mathrm{O}(\mathrm{g}) \leftrightarrow 2 \mathrm{HCl}(\mathrm{g})+1 / 2 \mathrm{O}_{2} \text { (Co catalyst) } & 100{ }^{\circ} \mathrm{C} \\ 2 \mathrm{VCl}_{2}+2 \mathrm{HCl} \leftrightarrow 2 \mathrm{VCl}_{3}+\mathrm{H}_{2} & 300{ }^{\circ} \mathrm{C}\end{array}$

In the "wet" variant, hydrogen is generated from an aqueous solution of $\mathrm{HCl}$ as shown in equations 12-14. The advantage of this process is that there is no need to remove $\mathrm{HCl}$ from $\mathrm{O}_{2}$ since the products of reverse Deacon reaction (eq 13) are condensed to accommodate the decomposition of $\mathrm{HCl}$ at $30^{\circ} \mathrm{C}$, as shown in eq 14 .

$$
\begin{array}{ll}
2 \mathrm{VCl}_{3} \leftrightarrow 2 \mathrm{VCl}_{2}+\mathrm{Cl}_{2} & >525^{\circ} \mathrm{C} \\
\mathrm{Cl}(\mathrm{g})+\mathrm{H}_{2} \mathrm{O} \leftrightarrow 2 \mathrm{HCl}+1 / 2 \mathrm{O}_{2} \text { (Co catalyst) } & 300{ }^{\circ} \mathrm{C} \\
2 \mathrm{VCl}_{2}+2 \mathrm{HCl}(\mathrm{aq}) \leftrightarrow 2 \mathrm{VCl}_{3}(\mathrm{aq})+\mathrm{H}_{2} & 30{ }^{\circ} \mathrm{C}
\end{array}
$$

Although the "wet" process seems to be a potentially more functional cycle due to the lack of required chemical separations, it is lower in efficiency when the heat demand of the steam is factored in. In fact, the "dry" process is more efficient theoretically, as long as the outlined chemical separations can be performed using little energy.

\subsubsection{Magnesium-lodine Cycle}

The magnesium-iodine cycle is a four step purely thermochemical cycle based on the oxidation-reduction loops of magnesium and iodine, as shown in the following equations.

$$
\begin{array}{ll}
6 / 5 \mathrm{MgO}(\mathrm{s})+6 / 5 \mathrm{I}_{2}(\mathrm{l}) \leftrightarrow 1 / 5 \mathrm{Mg}\left(\mathrm{IO}_{3}\right)_{2}(\mathrm{~s})+\mathrm{MgI}_{2}(\mathrm{aq}) & 120{ }^{\circ} \mathrm{C} \\
1 / 5 \mathrm{Mg}\left(\mathrm{IO}_{3}\right)_{2}(\mathrm{~s}) \leftrightarrow 1 / 5 \mathrm{MgO}(\mathrm{s}) 1 / 5 \mathrm{I}_{2}(\mathrm{~g})+1 / 2 \mathrm{O}_{2}(\mathrm{~g}) & 600{ }^{\circ} \mathrm{C} \\
\mathrm{MgI}_{2} \cdot 6 \mathrm{H}_{2} \mathrm{O}(\mathrm{s}) \leftrightarrow \mathrm{MgO}(\mathrm{s})+5 \mathrm{H}_{2} \mathrm{O}(\mathrm{g})+2 \mathrm{HI}(\mathrm{g}) & 450{ }^{\circ} \mathrm{C} \\
2 \mathrm{HI}(\mathrm{g}) \leftrightarrow \mathrm{H}_{2}(\mathrm{~g})+\mathrm{I}_{2}(\mathrm{~g}) & 450{ }^{\circ} \mathrm{C}
\end{array}
$$

In each of the four steps, there are requirements for chemical separations. In eq 15, it has been noted by Gadala-Maria (University of South Carolina) that the separation of $\mathrm{MgI}_{2}$ from the $\mathrm{Mg}\left(\mathrm{IO}_{3}\right)_{2}$ is not complete. Shindo et.al. determined that the concentration and the stoichiometry 
of the reaction is important to performing a clean conversion. ${ }^{\mathrm{h}}$ For instance, if the reaction is run with a relatively lower ratio of $\mathrm{I}_{2}$ to $\mathrm{MgO}$ under water limiting (concentrated) conditions, conversion to $\mathrm{Mg}\left(\mathrm{IO}_{3}\right)_{2}$ is poor and an undesired side reaction produced non-useful products. Increasing the $\mathrm{I}_{2} / \mathrm{MgO}$ ratio and keeping the solution of $\mathrm{MgI}_{2}$ diluted to $40-50 \%$ eliminates the side product and gives anhydrous $\mathrm{Mg}\left(\mathrm{IO}_{3}\right)_{2}$ in 80-90\% yield. The separation of the iodate from the iodide is simple filtration due to the fact that the iodate precipitates. However this separation is not complete and some iodate remained in solution. To address this problem, Gadala-Maria is considering electrodialysis.

Separation of the $\mathrm{MgI}_{2}$ solution is required to provide the feed to eq 17. This solution, once iodate is removed, consists of leftover iodine, $\mathrm{MgI}_{2}$, and water. Shindo discussed using simple distillation under ambient pressure to drive off both the water and iodine as vapors, which can be separated by condensation.

In eq 16, there is a need to separate $\mathrm{O}_{2}$ from iodine. Condensation of the iodine can be easily performed through cooling of the product stream. Recycle of the iodine to eq 15 could be done below the boiling point of iodine $\left(184^{\circ} \mathrm{C}\right)$ allowing effective removal of $\mathrm{O}_{2}$ at this point.

In eq 17, an aqueous solution of $\mathrm{HI}$ is formed that must be concentrated prior to the $\mathrm{HI}$ decomposition (eq 18). This separation can be problematic due to the azeotrope that exists at 57 $\% \mathrm{HI}$ content. Techniques such as distillation cannot be used to further concentrate the HI solution. This is a problem that exists in the S-I process and has been addressed using three approaches, albeit the S-I issue is further complicated by the elemental iodine content. First, reactive distillation is a process in which hydrogen is directly generated by decomposition of HI without significant concentration or removal of iodine, which of course is not an issue for the Mg-I cycle. Second, extractive distillation is a two step process that uses added concentrated phosphoric acid into $\mathrm{HI}_{\mathrm{x}}$ (iodine containing aqueous $\mathrm{HI}$ ) which allows for extraction and recycle of iodine. ${ }^{\mathrm{i}}$ The resulting HI, phosphoric acid, and water solution is distilled to obtain concentrated HI. Third, membrane processes for direct removal of water from HI solutions has

\footnotetext{
${ }^{\text {h }}$ Y. Shindo, N.Ito, K.Haraya, T. Hakuta, H. Yoshitome, “Thermal Efficiency of the Magnesium-Iodine Cycle for Thermochemical Hydrogen Production”, Int. J. Hydrogen Energy, 1983, 7, 509.

i J.H. Norman, G.E. Besenbruch, D.R. O'Keefe, “Thermochemical Water-Splitting for Hydrogen Production”, Report \# GRI80/0105, March 1981.
} 
INL/EXT-07-13099

been studied. ${ }^{\mathrm{j}, \mathrm{k}}$ In this work, pervaporation was used to concentrate HI by selective removal of water using Nafion ${ }^{\circledR}$ membranes. Later work has revealed that $\mathrm{HI}$ may be concentrated up to $80 \%$ at temperatures as high as $140{ }^{\circ} \mathrm{C}$ using this process. Once the $\mathrm{HI}$ is sufficiently concentrated, it may be dissociated over a catalyst to yield hydrogen. Early reports ${ }^{1}$ have studied catalysts such as platinum on carbon; however later work has shown that activated carbon is also effective. $^{\mathrm{m}}$

\subsubsection{Copper-Chlorine Cycle}

Lewis discusses the Copper-Chlorine cycle in terms of two variants. The first involves four reactions as shown below:

$$
\begin{array}{ll}
2 \mathrm{CuCl}(\mathrm{aq}) \leftrightarrow \mathrm{CuCl}_{2}(\mathrm{aq})+\mathrm{Cu}(\mathrm{s}) & 25{ }^{\circ} \mathrm{C} \\
2 \mathrm{Cu}(\mathrm{s})+2 \mathrm{HCl}(\mathrm{g}) \leftrightarrow 2 \mathrm{CuCl}(\mathrm{l})+\mathrm{H}_{2}(\mathrm{~g})(\text { electrochemical) } & 450{ }^{\circ} \mathrm{C} \\
2 \mathrm{CuCl}_{2}(\mathrm{~s})+\mathrm{H}_{2} \mathrm{O}(\mathrm{g}) \leftrightarrow \mathrm{Cu}_{2} \mathrm{OCl}_{2}(\mathrm{~s})+2 \mathrm{HCl}(\mathrm{g}) & 350-375^{\circ} \mathrm{C} \\
\mathrm{Cu}_{2} \mathrm{OCl}_{2}(\mathrm{~s}) \leftrightarrow 2 \mathrm{CuCl}(\mathrm{l})+1 / 2 \mathrm{O}_{2}(\mathrm{~g}) & 450-550{ }^{\circ} \mathrm{C}
\end{array}
$$

In this variant, hydrogen is generated from the electrochemical oxidation of copper to yield $\mathrm{Cu}^{1+}$, which is subsequently oxidized to $\mathrm{Cu}^{2+}$ and reduced to $\mathrm{Cu}$ metal in aqueous solution, as shown in eq 19. Combining of these two steps provides eq 23, which directly generates hydrogen from $\mathrm{CuCl}$ in an electrochemical process.

$2 \mathrm{CuCl}(\mathrm{aq})+2 \mathrm{HCl} \leftrightarrow \mathrm{CuCl}_{2}(\mathrm{aq})+\mathrm{H}_{2}(\mathrm{~g})$ (electrochemical) $\quad 25^{\circ} \mathrm{C}$

\footnotetext{
${ }^{j}$ C. J. Orme, M. G. Jones, and F. F. Stewart, "Pervaporation of Water from Aqueous HI using Nafion ${ }^{\circledR}-117$ Membranes for the Sulfur-Iodine Thermochemical Water Splitting Process", J. Membr. Sci. 2005252 (1-2), 245.

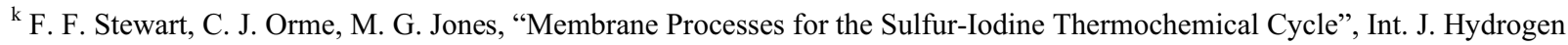
Energy 2007, 32, 457-462.

${ }^{1}$ Y.Oosawa, "The Decomposition of Hydrogen Iodine and Separation of the Products by the Combination of an Adsorbent with Catalytic Activity and Temperature-swing Method”, Bull Chem. Soc. Jpn., 1981, 54, 2908.

${ }^{\mathrm{m}}$ D. M. Ginosar, Private communication.
} 
INL/EXT-07-13099

The choice of which variant will be the most efficient depends on the development of the electrochemical step in terms of cell voltage and current density, which has not been completely performed at this time.

Parasitic reduction of $\mathrm{CuCl}_{2}$ to $\mathrm{CuCl}$ during reaction 21 is an issue that has been raised. In this reduction, $\mathrm{Cl}_{2}$ is generated and the reincorporation of this material into the cycle represents an additional reaction step that must be addressed. If it were chosen to not recycle this chlorine, separation of this gas from $\mathrm{HCl}$ could be problematic if it were judged to be necessary. It is not clear whether reaction 22 is possible in the presence of excess $\mathrm{Cl}_{2}$.

Incomplete conversion in eq 19 will also lead to aqueous mixtures of $\mathrm{Cu}^{1+}$ and $\mathrm{Cu}^{2+}$, along with the desired $\mathrm{Cu}^{0} . \mathrm{Cu}^{0}$ precipitates from solution, thus obviating a separation step; however the separation of $\mathrm{Cu}$ ions is somewhat more problematic. Perhaps the most effective solution would be to modify the reaction conditions such that conversion is enhanced. Otherwise, selective absorbents for divalent cations could be employed.

\subsubsection{Calcium-Bromine Cycle}

The calcium-bromine cycle is a three step cycle using an electrolytic hydrogen generation step where $\mathrm{HBr}$ is dissociated. The three steps are shown below:

$$
\begin{array}{ll}
\mathrm{CaO}+\mathrm{Br}_{2}(\mathrm{~g}) \leftrightarrow \mathrm{CaBr}_{2}+1 / 2 \mathrm{O}_{2}(\mathrm{~g}) & 740^{\circ} \mathrm{C} \\
3 \mathrm{CaBr}_{2}(\mathrm{l})+\mathrm{H}_{2} \mathrm{O}(\mathrm{g}) \leftrightarrow\left(\mathrm{CaBr}_{2}\right)_{2} \cdot \mathrm{CaO}(\mathrm{s})+2 \mathrm{HBr}(\mathrm{g}) & 550{ }^{\circ} \mathrm{C} \\
2 \mathrm{HBr} \leftrightarrow \mathrm{Br}_{2}(\mathrm{~g})+\mathrm{H}_{2}(\mathrm{~g})(\text { electrochemical) } & 55^{\circ} \mathrm{C}
\end{array}
$$

In this cycle, $\mathrm{HBr}$ is regenerated from the reaction of $\mathrm{CaBr}_{2}$ with water, and $\mathrm{CaBr}_{2}$ is prepared from $\mathrm{CaO}$ using the bromine generated from the electrochemical step. Lewis indicates that none of the chemical separations required for this cycle are difficult; however they do require some attention. First, drying of the $\mathrm{CaBr}_{2}$ hydrolysis product $(\mathrm{HBr})$ could improve the overall efficiency of the process; however the electrochemical step is not stopped by the inclusion of some water. This separation most likely can be done using a membrane; however the temperature must be lowered significantly. Proven membrane technologies for de-watering acidic solutions function only up to about $150^{\circ} \mathrm{C}$. Higher temperatures lead to membrane 
INL/EXT-07-13099

degradation and technologies that can withstand higher temperatures, in general, would not be expected to exhibit selectivity in this separation.

\section{PROJECT SUMMARY}

Technologies studied during FY2007 include pervaporation processes for concentration of $\mathrm{H}_{2} \mathrm{SO}_{4}$ and $\mathrm{HI}$, and feasibility studies for both the separation of $\mathrm{SO}_{2} / \mathrm{O}_{2}$ and for a $\mathrm{CMR}$ for the decomposition of HI with concomitant separation of product hydrogen. For the HI concentration work, it has been determined that high vacuum is not required. Higher backside pressures provide the requisite driving force to perform the separation. In fact, the water permeability through both Nafion-117® and Nafion-112® membranes at relevant feed acid concentrations does not significantly change with increasing backside pressure (lower driving force). Little changes in permeability with respect to membrane thickness also suggest that the mechanism of water transport is the same regardless of thickness. Using the permeabilities calculated as a function of feed water concentration allows for the prediction of membrane performance (flux) as a function of the membrane thickness. From this work, it has been estimated that performance greatly increases as the membrane thickness is decreased. Thus, key tasks that need to be addressed are 1) solution casting of Nafion to obtain thinner membranes, and 2) characterization of their performance. For the FY2008 workscope, a task has been included that addresses these issues.

Application of the HI concentration technology to aqueous sulfuric acid was performed. Nafion-112 $®$ and Nafion-117® membranes operating at $100^{\circ} \mathrm{C}$ and $120^{\circ} \mathrm{C}$ were characterized. Separation factors, in general, are higher than those observed for HI/water under similar conditions suggesting that sulfuric acid is less permeable through these membranes than is HI. Comparison of water fluxes and permeabilities between the two feeds yielded little difference suggesting that the mechanism of water transport is similar, which is not unexpected. Further, the data suggests that other mineral acids, such as phosphoric acid associated with the extractive distillation system, also could be concentrated using this technology. Application of thinner membranes to this process also would be advantageous.

A paper study of the applicability of polymeric membranes to $\mathrm{SO}_{2} / \mathrm{O}_{2}$ membranes revealed that rubbery materials with glass transition temperatures below room temperature may 
offer high permeability of $\mathrm{SO}_{2}$ and high separation factors. This conclusion was derived using $\mathrm{O}_{2}$ permeability data taken from pure gas experiments and estimated $\mathrm{SO}_{2}$ permeability data. To demonstrate applicability to the S-I ILS, pure and mixed gas experiments on the most promising membranes should be performed.

During 2007, the configuration of a CMR for the dissociation of HI with selective removal of hydrogen was selected for study. Driving this type of technology is the equilibrium limited nature of the HI decomposition reaction where conversions are only 5-10\%. To increase the efficiency of the reaction, a CMR has been proposed which will force greater conversion by removal of product. This configuration proposed for lab-scale studies is the commonly used tube and shell design. During FY2008, tube substrates will be selected and polymers identified as permeable to hydrogen at $300{ }^{\circ} \mathrm{C}$ (as identified during the FY2006 effort) will be coated on to the candidate substrates, followed by characterization using both pure and mixed gas characterization procedures. Once a stable polymer-tube composite is formed and characterized, catalyst loading experiments and tests against HI feeds can be conducted.

A study also was performed on examining the chemical separations needs for the alternate cycles. None of the cycles discussed have separations that are potential "show stoppers", although some of the indicated separations will be challenging to perform. For example, the separation of $\mathrm{O}_{2}$ from $\mathrm{Br}_{2}$ at $740{ }^{\circ} \mathrm{C}$ as indicated in the Calcium Bromide cycle may be difficult due to the gaseous nature of these two components. This issue is magnified due to the temperature involved in this particular step. Additionally, the separation of $\mathrm{Cu}$ ions discussed as a part of the Copper-Chlorine cycle also poses challenges; although a sorption technique specific for divalent cations may have utility.

The majority of the cycles involve separations that are either more achievable or more developed. For the Magnesium-Iodine cycle, many of the required separations are also common with the more developed Sulfur-Iodine, thus a targeted research effort may not be required. Furthermore, the oxygen separation required for the Hybrid Chlorine cycle should be able to be performed using existing mixed metal oxide membranes that have shown good selectivity favoring oxygen. 
INL/EXT-07-13099

\section{PUBLICATION AND PRESENTATIONS}

1. Frederick F. Stewart, Christopher J. Orme, and Michael G. Jones, "Membrane Processes for the Sulfur-Iodine Thermochemical Cycle", International Journal of Hydrogen Energy 2007, 32, 457462.

2. Christopher J. Orme and Frederick F. Stewart, "Pervaporation of Water from Aqueous Hydriodic Acid and Hydriodic Acid/Iodine Mixtures Using Nafion Membranes", Accepted for publication in Journal of Membrane Science, 2007.

3. Christopher J. Orme, John R. Klaehn, and Frederick F. Stewart, "Membrane Separation Processes for the Benefit of the Sulfur-Iodine and Hybrid Sulfur Thermochemical Cycles”, Submitted to International Journal of Hydrogen Energy, 2007.

4. Frederick F. Stewart and Christopher J. Orme, “Advances in Acid Concentration Membrane Technology for the Sulfur-Iodine Thermochemical Cycle" Presented to the Annual AICHE Meeting, Nuclear Engineering Division, San Francisco, CA, November 2006.

5. Frederick F. Stewart and Christopher J. Orme, "Membrane Separations Technology for the Sulfur-Iodine Thermochemical Cycle" To be presented to the Annual AICHE Meeting, Nuclear Engineering Division, Salt Lake City, UT, November 2007.

6. Frederick F. Stewart, and Christopher J. Orme, "Dehydration of Hydriodic Acid and Sulfuric Acid by Pervaporation" To be presented to the Annual AICHE Meeting, Separations Division, Salt Lake City, UT, November 2007. 